Wright State University

CORE Scholar

\title{
The Usefulness of Consumer Sentiment: Assessing Construct and Measurement
}

\author{
Paul M. Kellstedt
}

Suzanna Linn

A. Lee Hannah

Wright State University - Main Campus, lee.hannah@wright.edu

Follow this and additional works at: https://corescholar.libraries.wright.edu/political_science

Part of the Political Science Commons

\section{Repository Citation}

Kellstedt, P. M., Linn, S., \& Hannah, A. L. (2015). The Usefulness of Consumer Sentiment: Assessing Construct and Measurement. Public Opinion Quarterly, 79 (1), 181-203.

https://corescholar.libraries.wright.edu/political_science/34

This Article is brought to you for free and open access by the Political Science at CORE Scholar. It has been accepted for inclusion in Political Science Faculty Publications by an authorized administrator of CORE Scholar. For more information, please contact library-corescholar@wright.edu. 


\title{
THE POLLS-REVIEW \\ THE USEFULNESS OF CONSUMER SENTIMENT: ASSESSING CONSTRUCT AND MEASUREMENT
}

\author{
PAUL M. KELLSTEDT* \\ SUZANNA LINN
}

\section{A. LEE HANNAH}

\begin{abstract}
Given the scholarly and popular prominence of the concept of consumer confidence, it is striking that there are no examinations of the quality of the most commonly used measure of the concept - the University of Michigan's Index of Consumer Sentiment (ICS). In this study, we assess the usefulness of consumer sentiment as a construct and a measure (or measures). We also identify the best way to consider its role in consumer behavior. This brings us to a consideration of fundamental questions about the reliability and validity of consumer sentiment measures. Our purpose is to provide evidence on this score. Our analyses suggest that the ICS is a reliable indicator of consumer confidence. The measure exhibits substantial face validity, but the index itself (though not its components) falls short in terms of its predictive validity with regard to spending on durable goods.
\end{abstract}

Americans' subjective evaluations of the economy's recent trajectory, and their expectations about its likely future prospects - a concept referred to as consumer sentiment or consumer confidence 1 - have become key ingredients in the everevolving business of predicting the future of the economy as well as the futures of the politicians entrusted with managing it. Much like the eager anticipation that

PAul M. Kellstedt is an associate professor of political science at Texas A\&M University, College Station, TX, USA. SUZANNA LINN is a professor of political science at Pennsylvania State University, University Park, PA, USA. A. LeE HANNAH is a PhD candidate in political science at Pennsylvania State University, University Park, PA, USA. An earlier version of this paper was presented in a seminar at Stony Brook University. The authors thank Matthew Lebo and Helmut Norpoth for useful suggestions. *Address correspondence to Paul M. Kellstedt, Texas A\&M University, Department of Political Science, College Station, TX 77843-4348, USA; e-mail: kellstedt@ pols.tamu.edu.

1. We use the terms "consumer sentiment" and "consumer confidence" interchangeably throughout the paper, consistent with the ways the words are used in the press. 
precedes the release of monthly reports on jobs or inflation, the monthly readings of consumer confidence are widely reported in the news and discussed extensively by the commentariat class. As often as not, shifts in consumer confidence are described as "surprising." The information contained in the monthly sentiment figures is viewed by some as so valuable that certain traders are willing to pay $\$ 4,500$ a year for early access to a leading measure of consumer confidence: the University of Michigan's Index of Consumer Sentiment (Antilla 1991). Furthermore, scholarly evidence continues to mount that consumer sentiment influences evaluations of politicians, public liberalism, trust in government, and election outcomes (MacKuen, Erikson, and Stimson 1992; Durr 1993; Erikson, MacKuen, and Stimson 2002; Keele and Kelly 2006). The implication is that surveys of consumer confidence contain meaningful information for politics and for the economy itself.

What remains unclear, however, is the utility of survey measures of consumer confidence as either reflective or predictive measures of consumer behavior in the marketplace. Although the survey results are reported as harbingers of future spending, many argue that "the surveys act more like mirrors than crystal balls" (Cohen 1995; Garner 1991). Academic research echoes this finding (Adams and Green 1965; Loria and Brito 2004). The general tenor of the research suggests that sentiment plays a small role (Carroll, Fuhrer, and Wilcox 1994; Bram and Ludvigson 1998; Jansen and Nahuis 2003; Easaw and Heravi 2004; Bryant and Macri 2005; Easaw, Garratt, and Heravi 2005), ${ }^{2}$ or does so only when changes in sentiment are unusually large (Desroches and Gosselin 2002) or during extraordinary economic or political events (Garner 1991; Throop 1992). But some economists suggest a larger role for sentiment in the case of particular types of consumption, such as durablegoods consumption (Blanchard 1993; Hall 1993; Eppright, Arguea, and Huth 1998; Adrangi and Macri 2011), though not for other forms of consumption or economic activity. Perhaps the following best sums up the general sentiment among economists: When the US Department of Commerce announced that it was revising its Index of Leading Economic Indicators to include consumer evaluations, the addition was contested by many economists (Morin 1992).

There is a consensus that consumer sentiment drives political behavior. Scholars have demonstrated that the American electorate evaluates the president (MacKuen, Erikson, and Stimson 1992) and Congress (Durr, Gilmour, and Wolbrecht 1997) on the basis of prospective economic assessments of the national economy. Erikson, MacKuen, and Stimson (2002) show that aggregate appraisals of the macro-economy drive US presidential election outcomes. Similar results have been found cross-nationally (Hardouvelis and Thomakos 2008). Research has also demonstrated a persistent relationship between economic assessments and partisanship at the individual level (Ladner and Wlezien 2007). ${ }^{3}$

2. See Easaw, Garratt, and Heravi (2005) for comparable work in the UK context, and Bryant and Macri (2005) for parallel work in Australia.

3. There is also evidence that political behavior influences consumer sentiment (see Wlezien, Franklin, and Twiggs 1997; De Boef and Kellstedt 2004; Enns, Kellstedt, and McAvoy 2012). 
These findings — at least in the American context—all hinge on the assumption that consumer sentiment is measured in a reliable and valid way. And yet, the reliability and validity of the most common measure of the concept of consumer sentiment- the University of Michigan's Index of Consumer Sentiment- has not been subjected to rigorous scrutiny. In what follows, we assess the usefulness of consumer sentiment as a construct and a measure (or measures) in order to identify the best way to consider the role of sentiment in consumer behavior. This brings us to a consideration of fundamental questions about the reliability and validity of consumer sentiment measures. Our purpose is to provide evidence on this score.

We proceed as follows. First, we describe the historical origins of the concept and measures of consumer sentiment. Then we describe how the concept has been measured. Next, we examine two forms of reliability of the University of Michigan's Index of Consumer Sentiment (ICS), evaluating first how the ICS and its component measures are related (internal reliability), and second how the Conference Board's Consumer Confidence Index (CCI) and ICS are related as time unfolds (parallel-form reliability). We then turn to an evaluation of the validity of the ICS, with a particular focus on the comparative evidence for the ICS as a whole relative to the individual components taken together. We ask which measures best forecast consumer spending (content/predictive validity). We conclude with prescriptive advice for practitioners who use measures of consumer confidence in their models.

\section{The Origins of Consumer Sentiment as a Concept and a Measure}

Consumer sentiment is a concept borne out of the field of behavioral economics at its modern-day (post-World War II) inception. George Katona (for example, see Katona 1975), along with other pioneers in the field, including Nobel laureates Herbert Simon (1951 1955) and Daniel Kahneman (Kahneman and Tversky 1973), challenged the prevailing view in economics that humans are rational beings exhibiting optimizing behavior (Katona 1975; Hosseini 2003). Broadly, they argued that economic processes result from human behavior - the motives, attitudes, and expectations of human beings influence their economic behavior. In 1944, in an effort to demonstrate the importance of consumers' attitudes for spending and saving decisions, Katona convinced the Board of Governors at the Federal Reserve to add attitudinal questions to its surveys of consumers. ${ }^{4}$ Katona directed the survey, which was prepared and fielded by the University of Michigan's Survey Research Center, and used these data to demonstrate a "clear relationship" between attitudes and consumer behavior (Likert 1972). This early survey has become the

4. Katona argued that survey respondents were more likely to reveal information about their incomes and spending habits if they were first asked about their evaluations of their own and national economic conditions. 
Michigan Survey of Consumers, the data from which the widely anticipated ICS is calculated.

Katona made a simple argument: When deciding whether to spend (now or later) on discretionary goods, consumers base their decisions on both their ability to purchase the goods and their "willingness" to do so. Income and asset assessments determine ability, and assessments of future income determine willingness. The two together, then, should determine spending, in particular on durable goods. ${ }^{5}$ Additionally, because assessments of the economic future are uncertain, the consumer faces some risk associated with a poor estimate in the wrong direction: too little savings, too much debt, mortgage foreclosure, inability to purchase necessities, and so on. Uncertainty about the future should then inhibit spending by raising its risk.

Each of these mechanisms of influence suggests an important role for both economic and noneconomic information in determining spending decisions. Precisely what those noneconomic factors are has received little attention (but see De Boef and Kellstedt 2004). However, they might include the decisions and (in)actions of political actors-legislative stalemate, government shutdowns, and uncertain election outcomes, as well as widespread views of malfeasance of those at the top of the political economy; when those we hold responsible for the performance of the economy cannot produce economic growth and are mired in politics, there is little reason for consumers to be optimistic. Consumer attitudes are also likely to be influenced by unexpected events whose economic effects are unpredictable and are not quickly reflected in economic indicators: wars, terrorism, and natural disasters (De Boef and Kellstedt 2004).

\section{Measurement Details: The Index of Consumer Sentiment and the Consumer Confidence Index}

In our analysis, we focus primarily on the University of Michigan's Index of Consumer Sentiment (ICS) because it is by far the most prominent measure used in the literature, though we also consider, for comparative purposes, the Conference Board's Consumer Confidence Index (CCI). ${ }^{6}$ The ICS is calculated from respondents' assessments of their personal finances (retrospective and prospective), national economic performance (one and five years out), and (current) buying conditions and is designed to capture "optimism and certainty" or "pessimism and uncertainty" felt by consumers (Curtin 2008). The second measure of overall sentiment is the Consumer Confidence Index

5. Nondiscretionary purchases cannot be easily postponed and therefore should be inelastic with regard to assessments of future income. Purchases of durable goods can often be delayed until consumers feel that less risk is associated with reducing savings or borrowing to make purchases. 6. A more detailed comparison of the two indexes can be found in Ludvigson (2004). 
(CCI), distributed by the Conference Board each month. It is based on answers to five questions asking respondents for evaluations of job prospects and business conditions, both now and in the future, as well as family income.

Specifically, the ICS is based on responses to the five questions given in column 2 of table 1 , which are asked in a nationally representative telephone survey of 500 respondents who are reinterviewed six months later by the University of Michigan Survey Research Center. ${ }^{7}$ Roughly 60 percent of the sample in any month is interviewed for the first time. The marginals are released on the second Friday every month, and are revised and rereleased the fourth Friday of the same month. The Survey began annually in the 1940s, became quarterly in 1958, and has been administered monthly since 1978 . For each of the five indicators, a series is created by summing the percentage of positive responses, subtracting the percentage of negative responses, and adding 100. The ICS averages these individual "diffusion" values, weighting each indicator equally. Finally, the results are converted to the base period and 2 is added to correct for sample-design changes. ${ }^{8}$

7. The monthly Survey of Consumers is an ongoing nationally representative survey based on approximately 500 telephone interviews with adult men and women living in households in the 48 coterminous United States (plus the District of Columbia). The sampling frame includes a rotating panel sample design in which an independent cross-section sample of households is drawn each month. Each respondent is then reinterviewed six months later. Approximately 60 percent of the sample in any given month is composed of new respondents, with 40 percent interviewed for a second time.

The sample is selected using a one-stage list-assisted RDD frame, which consists of all hundred series that have at least one listed household number and forms a subset of approximately 40 percent of the total possible hundred series that can be formed from all Area Code/Exchanges in the Bellcore system. The incidence of working household numbers is about 50 percent in the set of listed hundred series. In conjunction, the sample is selected using the GENESYS Sampling System to produce (geography and urbanicity) stratified, one-stage, equal probability samples of telephone households in the contiguous United States (48 states and the District of Columbia). The list-assisted RDD design provides for an equal probability sample of all telephone households. Probability methods are also used to select one adult as the designated respondent within the household.

Corrections for non-telephone ownership, survey nonresponse, and panel attrition are made through post stratification by selected demographic characteristic, stratifying separately for the RDD and reinterview portions of the sample. Data from the Current Population Surveys conducted by the Census are used to adjust for variations in the age and income distributions observed in the monthly samples. The data are weighted for households. The expected sampling error is $+/-5$ percentage points for the monthly sample size of approximately 500 . Monthly response rates, provided by SCA, have fallen considerably since the beginning of the time period under analysis here. Typical response rates were in the vicinity of 70 percent during the 1980s and declined slowly, reaching rates of around 60 percent by 2000. Since then, the decline has been more precipitous, with response rates rarely above 40 percent since 2010. (Exact response rates by month are available from the authors.) See http://www.sca.isr.umich.edu/survey-info.php for more details.

8. The ICS also releases two subindices: The Index of Current Conditions (ICC) uses the first two questions from table 1. The Index of Consumer Expectations (ICE) is based on the last three questions from the same table. See the Report on Index Value Calculations at http://www.sca.isr. umich.edu/ for more details and the questionnaire. 
Table 1. Consumer Sentiment Survey Data

\begin{tabular}{ll}
\hline University of Michigan Survey of & Conference Board Consumer Confidence \\
Consumer Attitudes and Behavior & Survey \\
\hline
\end{tabular}

Retrospective evaluations

1. Do you think now is a good or bad time for people to buy major household items? [good time to buy; uncertain, depends; bad time to buy]

2. Would you say that you (and your family living there) are better off or worse off financially than you were a year ago? [better; same; worse]

\section{Prospective evaluations}

3. Now, turning to business conditions in the country as a whole, do you think that during the next 12 months, we'll have good times financially or bad times or what? [good times; uncertain; bad times]

4. Looking ahead, which would you say is more likely? That in the country as a whole we'll have continuous good times during the next five years or so, or that we'll have periods of widespread unemployment or depression, or what? [good times; uncertain; bad times]

5. Now, looking ahead, do you think that a year from now, you (and your family living there) will be better off financially, or worse off, or just about the same as now? [better; same; worse]

How would you rate present general business conditions in your area? [good; normal; bad]

What would you say about available jobs in your area right now? [plentiful; not so many; hard to get]

Six months from now, do you think business conditions in your area will be [better; same; worse]?

Six months from now, do you think there will be [more; same; fewer] jobs available in your area?

How would you guess your total family income to be six months from now? [higher; same; lower]

We present the index and its components in figure 1. The ICS is given in the top left-hand corner. The series is seldom in territory above the 100 "neutral" point, averaging about 87 (standard deviation 12.4), with exceptions in the latter half of the 1990s and early 2000s, before taking its noted and lengthy slide into some of its lowest values - but low values that are not exceptionally low by historical standards. There is an upswing at the end of the sample period. The panel in the top-right graphs personal retrospective evaluations, which vacillate around the 100 mark, averaging just above 107 (standard deviation 15.1), but like the ICS, after early 2000 they begin an almost continuous slide downward, reaching 60 before turning upward and reaching 91 in early 2012. Prospective personal evaluations (first column, row two) exhibit 

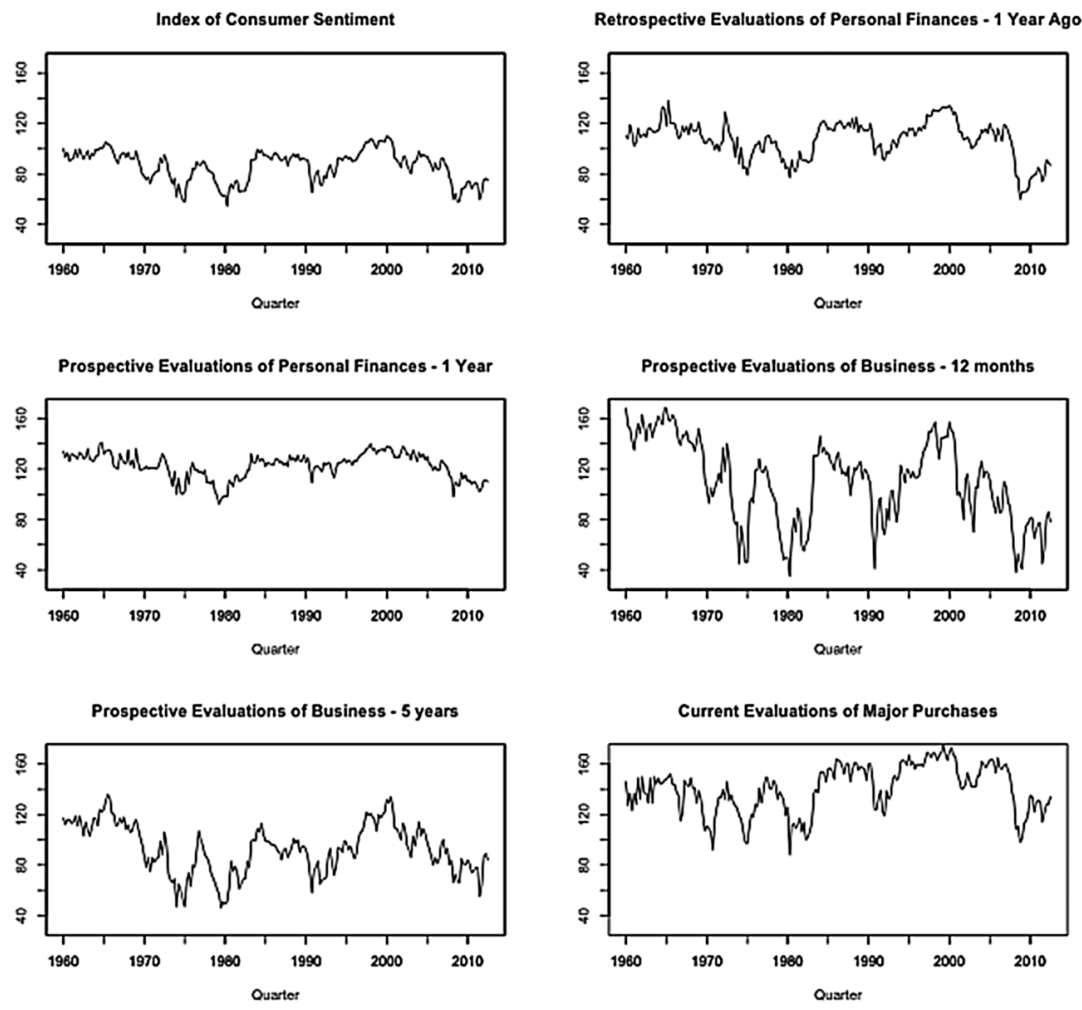

Figure 1. University of Michigan Index of Consumer Sentiment and Its Component Series, 1960:Q1-2012:Q3.

the least variance of the components, by more than half (standard deviation 10.1 ), and tend to be relatively positive, with a mean of 122 . In contrast, to the right, one-year-out business expectations move about the most, with a standard deviation over 32 and a mean over 109. They share the pattern seen in all the series, with more negative evaluations beginning shortly after the election of George W. Bush in 2000. These evaluations began to improve after the election of Barack Obama in 2008, but began to falter as quickly as the others. In the bottom row on the left are five-year-out business evaluations. These are less positive-Americans' optimism does not extend far into the future. Mean evaluations drop to 92.7, with a standard deviation of approximately 20 . The now-common pattern of decline in evaluations after 2000 is again apparent, but with a more sawtooth-like pattern. Finally, on the bottom right are assessments of whether now is a good time to make a purchase of major appliances. These are durable goods, a point not lost on Katona (1975): the very things we can hold off buying when times are bad. It appears, though, that consumers did not decide that times were disproportionately poor for making these purchases; 
this index did not drop below 100 often in its history, and not until the very end of our sample period in the recent crisis. In fact, this component series has the highest mean, 140, and a relatively high standard deviation at 19 points.

The Consumer Confidence Survey has been conducted since 1967 for the Conference Board..$^{9}$ Questionnaires are mailed each month to a nationwide representative sample of 5,000 households, with a typical response of 3,500 completed surveys. ${ }^{10}$ The Consumer Confidence Index (CCI) is based on the five questions in column 3 of table 1. For each question, the number of positive responses is divided by the sum of the number of positive and negative responses and multiplied by 100 . Each diffusion index is converted to a base-year index and then averaged, weighting each equally. ${ }^{11}$ The Conference Board releases index values on the last Tuesday of each month and revises them at the end of the following month. Data exist bimonthly from 1966 to 1977, after which they become available monthly. ${ }^{12}$

\section{The Usefulness of the ICS as a Measure}

While inferences about the role of consumer sentiment are debated, the wider success of behavioral economics, Katona's premise, as well as the

9. TNS conducted the survey until September 2011. The Nielsen Company replaced TNS in February 2011. Analyses of data from the overlapping period suggest that the transition had no effect on the continuity of the data.

10. According to The Conference Board (https://www.conference-board.org/data/consumerdata. cfm), its Consumer Confidence Survey is based on a mail survey conducted using (since 2011) a probability-design random sample conducted by Nielsen (formally conducted by TNS). The sample frame is derived from files created by the US Postal Service. The frame is first stratified geographically within the Census division, after which a systematic sample of household addresses is selected and questionnaires mailed. They aim, according to the website, to have "approximately 3,000 completed" surveys. Post-stratification weights (for gender, income, geography, and age) and the US Census X-12 seasonal adjustment are then applied. No information is provided by the Conference Board about the precise number of questionnaires mailed or how they end up with 3,000 completed questionnaires.

According to Ludvigson $(2004,34)$, prior to the new sampling procedure, the Conference Board's Confidence Survey, conducted by TNS, was based on a sample of 5,000 drawn "from an original sample"-size unknown — "in which respondents agree to do the interviews." He reports that "on the last Tuesday of the survey month, the Conference Board formally releases its preliminary figures based on about 2,500 responses" (34).

We contacted the Conference Board for exact response rates. Unfortunately, the organization declined to provide those and, in correspondence with us, maintained that on average, 60-70 percent of those sampled returned the questionnaire. Of course, this is not properly a "response rate." It almost certainly does not account for the low acceptance rate of respondents into their recruited panel. The figure from the Conference Board is likely a completion rate from their pre-recruited panel. After the transition to the new method, the response rate "has averaged around 26-28\%."

11. Like the University of Michigan, the Conference Board also releases two subindices: The Present Situation Index is created in the same method as the CCI, using the first two questions; the Index of Consumer Expectations is created from the final three.

12. See http://www.conference-board.org/. 
proliferation of measures and attention of the press, suggest that it is worth asking a set of questions that has attracted little attention. How reliable are different measures of sentiment, and how valid is any given measure of sentiment?

The usefulness of a construct stems from its ability to tell us something new-that is, information that could not be gleaned from other sources. As conceived by Katona (1975), consumer sentiment captures the human element in consumption and savings decisions, which he deemed necessary for understanding these decisions. Therefore, it should both provide information independent of economic conditions and predict the behavior of consumers in the marketplace. These are issues of both construct and measure. Therefore, in order to assess the usefulness of consumer sentiment, we need to return to the very basic questions of the reliability and validity of measures of consumer sentiment.

The twin concerns of a measure's reliability and validity-that a construct is captured accurately - are of paramount importance. Without some assurance on these counts, the measure itself cannot be useful. Reliability-being free from unsystematic types of error (Didow and Franke 1984), being stable, dependable, trustworthy, and consistent (Worthen, Borg, and White 1993) — is not typically examined in time-series analysis. Validity-capturing the concept of interest-is also infrequently considered. In part, this is because, in time-series analysis, we seldom have multiple measures of a concept. But we can tackle these issues, in the first case because we have multiple measures of sentiment, and in the second because it is conceptually well defined so that we know what it should predict and how.

Our assessments of reliability and validity begin with the assumption that consumer sentiment is a unidimensional construct- "willingness to consume" - and that the Index of Consumer Sentiment (and, separately, the Consumer Confidence Index) measures that construct. We see how far this takes us before we examine the unique behavior of ICS components and their relationship to the Index of Consumer Sentiment. Such a procedure can be justified by appealing to the almost exclusive use of the overall Indices in (a) published research; (b) media attention; and (c) Katona's own work building the Index of Consumer Sentiment. ${ }^{13}$

\section{Reliability}

The reliability of a measure, at its core, revolves around how repeatable a measure is. In what follows, we examine two distinct conceptions of reliability: the more familiar internal reliability, and parallel-form reliability.

13. It is true that only the prospective components of the ICS are included in the Leading Economic Indicators Index, but the purpose of the LEI is forward looking while that of the ICS is to assess willingness to consume more generally. 
INTERNAL RELIABILITY

As a time series and as an index built of five component time series, one important aspect of the reliability of the ICS deals with its repeatability in terms of the relationship between the indicators and the index over time. That is, the more reliable the ICS is, the more it will be a function of the same components, to the same degrees, across time. If, by contrast, the components of the ICS contribute to the index to highly varying degrees - that is, with high correlations to the index at some points in time, and lower correlations to the index at other points in time-then to that extent, the index is less reliable.

Formally, this type of reliability is termed internal consistency. An index is internally consistent if each indicator measures the underlying construct and is therefore strongly correlated with the ICS. The usual course of action, in the cross-sectional world, is to look at a correlation matrix or compute an industry-standard measure of reliability (like Cronbach's alpha) to assess internal consistency. ${ }^{14}$ However, these assume away the question at hand by assuming constant correlations across time. Thus, we assess internal consistency using a model that estimates dynamic (or conditional) correlations, the Dynamic Conditional Correlation Generalized Autoregression Conditional Heteroscedasticity (DCC-GARCH, hereafter DCC) model. The DCC model estimates the conditional correlation between the two time series as a function of both the previous variability of each series and the previous correlation between them (Engle and Sheppard 2003; Lebo and Box-Steffensmeier 2008)..$^{15}$

We are interested in two sets of information from the DCC models. The first is the estimates of the conditional correlations themselves. These are extracted from the model given the estimated parameters and reveal the path the correlations follow over the time period for which the index is available. They provide visual evidence about the extent to which the index is a function of each indicator and the degree to which that relationship changes over time. The second set of information is the two DCC parameters. The first of these, $\beta$, gives us a sense of the persistence in the correlations-how much the relationship between the index and the indicator varies over time. The closer to 1.0 , the more persistent the conditional correlations, and the more consistent the relationship between the index and the component series over time. The second DCC parameter, $\alpha$, tells us how much "news" impacts the path of the correlations. Smaller news parameters are consistent with a more reliable

14. Another closely related measure of reliability is item total correlation, which measures the degree to which any given item is related to a total score, at any single point in time.

15. Briefly, the estimation process involves two steps. In the first step, univariate mean and variance models are fit for the ICS and each component, which removes the effects of the past on the current observation and produces estimates of the (conditional) volatility within the series. Conditional correlations are estimated using the standardized residuals from the univariate models as estimates in a time-varying correlation matrix. Thus, the estimated dynamic correlations are purged of that portion that is due simply to the shared dynamic patterns. The models were fit in $R$ using the rugarch and rmgarch packages (Ghalanos 2013). 
index. If $\beta=\alpha=0$, the conditional correlations equal the unconditional correlations, and the correlations are constant. ${ }^{16}$

The simple question of whether the index is a function of the components to the same degrees across time does not have a simple answer. The evidence is reported in table 2. All five of the index components show evidence of dynamic correlations, and thus have higher correlations at some times and not others. All of the index components exhibit high degrees of persistence in their correlations with the ICS, as evidenced by the $\beta$ coefficients of 0.80 or higher. The correlations evolve over time, but they do so quite slowly. The impact of news is unsurprisingly insignificant, substantively, and also statistically in most cases. The correlations between the ICS and its components do not appear to respond much to new information, but rather evolve slowly. We have, then, evidence that the conditional correlations are just that: conditional.

Graphing the correlations-see figure 2-provides additional information. It allows us to see which ICS-component pairs have the strongest correlations, to identify when correlations in the pairs are higher and lower, and to get a sense of the significance of the over-time dynamics. Expectations about future business conditions - both one and five years ahead — consistently exhibit the highest conditional correlations with the ICS, but they do not move in lockstep.

Statistical tests tell us that we can reject the null hypothesis that the correlations between these ICS-component pairs are constant, ${ }^{17}$ but there exists no formula for computing the standard error of the conditional correlations. Thus, to get a sense of the significance of the over-time variation in the correlations, we place a confidence interval around the estimate of the constant correlation between the series pairs. ${ }^{18}$ Doing so reveals that the range over which the conditional correlations move is typically constrained within a 95 percent confidence interval of the estimated constant correlation, giving us good reason to feel reassured about the internal reliability of the index. Still, there are times when four of the indicators-personal retrospective and prospective evaluations, and business expectations one and five years ahead-exhibit a unique relationship with the index. In all four cases, the biggest changes occur in the earlier time period. Notably, in the most recent period, when the conditional variance in the indicators is lower, the conditional correlations have grown. ${ }^{19}$

16. Such a finding would lead us to conclude that the index is highly reliable, but these are not the only empirical results that could lead to such an inference.

17. For all five pairings, the null hypothesis of constant correlations can be rejected at $p<.05$ for a variety of lag lengths.

18. The constant correlation is estimated from the filtered time series using the mean and variance models that served as the basis for the DCC GARCH model.

19. The dynamic correlations were particularly more volatile in the period of time (1960-1977) in which the survey was administered quarterly rather than monthly (1978 forward). In the earlier period, the average number of respondents in the samples was slightly smaller (mean $=1,438$ for the earlier period, 1,680 for the later period) and had a larger standard deviation (s.d. $=440$ for the earlier period, 357 for the later period). The reduction in volatility of the dynamic correlations may partly be a result of the reduction in measurement error due to the more frequent measurement of sentiment in recent years. 
Table 2. DCC GARCH Estimates for the Index of Consumer Sentiment with its Components (Quarterly, 1960-2012Q3); Index of Consumer Sentiment and Consumer Confidence Index (Quarterly, 1977-2012Q3)

\begin{tabular}{|c|c|c|c|c|c|c|}
\hline & $\begin{array}{c}\text { Personal } \\
\text { retrospections }\end{array}$ & $\begin{array}{c}\text { Personal } \\
\text { expectations }\end{array}$ & $\begin{array}{c}\text { One-year } \\
\text { national }\end{array}$ & $\begin{array}{l}\text { Five-year } \\
\text { national }\end{array}$ & $\begin{array}{c}\text { Durable } \\
\text { purchasing }\end{array}$ & $\begin{array}{l}\text { Consumer } \\
\text { confidence }\end{array}$ \\
\hline \multicolumn{7}{|l|}{ ICS } \\
\hline Constant & $\begin{array}{l}87.52 * * \\
(4.82)\end{array}$ & $\begin{array}{l}87.52 * * \\
(4.78)\end{array}$ & $\begin{array}{l}87.52 * * \\
(5.05)\end{array}$ & $\begin{array}{l}87.52 * * \\
(4.84)\end{array}$ & $\begin{array}{l}87.52 * * \\
(4.75)\end{array}$ & $\begin{array}{l}86.26 * * \\
(4.34)\end{array}$ \\
\hline AR (1) & $\begin{array}{l}0.92 * * \\
(0.03)\end{array}$ & $\begin{array}{l}0.92 * * \\
(0.03)\end{array}$ & $\begin{array}{l}0.92 * * \\
(0.03)\end{array}$ & $\begin{array}{l}0.92 * * \\
(0.03)\end{array}$ & $\begin{array}{l}0.92 * * \\
(0.03)\end{array}$ & $\begin{array}{l}0.92 * * \\
-\end{array}$ \\
\hline$a$ & $\begin{array}{c}0.07 \\
(0.05)\end{array}$ & $\begin{array}{c}0.07 \\
(0.05)\end{array}$ & $\begin{array}{c}0.07 \\
(0.05)\end{array}$ & $\begin{array}{c}0.07 \\
(0.05)\end{array}$ & $\begin{array}{c}0.07 \\
(0.05)\end{array}$ & $\begin{array}{c}0.07 \\
-\end{array}$ \\
\hline$b$ & $\begin{array}{l}0.74 * * \\
(0.10)\end{array}$ & $\begin{array}{l}0.74 * * \\
(0.10)\end{array}$ & $\begin{array}{l}0.74 * * \\
(0.10)\end{array}$ & $\begin{array}{l}0.74 * * \\
(0.10)\end{array}$ & $\begin{array}{l}0.74 * * \\
(0.10)\end{array}$ & $\begin{array}{c}0.74 * * \\
-\end{array}$ \\
\hline \multicolumn{7}{|l|}{ Component } \\
\hline Constant & $\begin{array}{r}111.22 * \\
(5.46)\end{array}$ & $\begin{array}{c}126.52 * * \\
(3.85)\end{array}$ & $\begin{array}{l}118.23 * * \\
(14.13)\end{array}$ & $\begin{array}{l}95.40 * * \\
(7.47)\end{array}$ & $\begin{array}{c}144.77 * * \\
(6.16)\end{array}$ & $\begin{array}{c}104.89^{* *} \\
(2.58)\end{array}$ \\
\hline $\mathrm{AR}(1)$ & $\begin{array}{l}0.71 * * \\
(0.08)\end{array}$ & $\begin{array}{l}0.61 * * \\
(0.07)\end{array}$ & $\begin{array}{l}0.93 * * \\
(0.03)\end{array}$ & $\begin{array}{l}0.91 * * \\
(0.03)\end{array}$ & $\begin{array}{l}0.71 * * \\
(0.07)\end{array}$ & $\begin{array}{l}0.64 * * \\
(0.16)\end{array}$ \\
\hline AR (2) & $\begin{array}{l}0.22 * * \\
(0.08)\end{array}$ & $\begin{array}{l}0.31 * * \\
(0.07)\end{array}$ & & & $\begin{array}{l}0.21 * * \\
(0.07)\end{array}$ & $\begin{array}{l}0.29^{+} \\
(0.15)\end{array}$ \\
\hline MA (1) & & & & & & $\begin{array}{l}0.58 * * \\
(0.13)\end{array}$ \\
\hline$a$ & $\begin{array}{c}0.20^{+} \\
(0.11)\end{array}$ & $\begin{array}{c}0.15^{+} \\
(0.09)\end{array}$ & $\begin{array}{c}0.11^{+} \\
(0.06)\end{array}$ & $\begin{array}{c}0.05^{+} \\
(0.05)\end{array}$ & $\begin{array}{c}0.01 \\
(0.03)\end{array}$ & $\begin{array}{l}0.40^{* *} \\
(0.13)\end{array}$ \\
\hline$a_{2}$ & & & & & $\begin{array}{c}0.23 \\
(0.17)\end{array}$ & \\
\hline$b$ & $\begin{array}{l}0.49^{* *} \\
(0.14)\end{array}$ & $\begin{array}{l}0.69 * * \\
(0.20)\end{array}$ & $\begin{array}{l}0.73 * * \\
(0.07)\end{array}$ & $\begin{array}{l}0.84 * * \\
(0.06)\end{array}$ & & $\begin{array}{l}0.41 * * \\
(0.09)\end{array}$ \\
\hline \multicolumn{7}{|c|}{ DCC parameters } \\
\hline$\alpha$ & $\begin{array}{c}0.05 \\
(0.04)\end{array}$ & $\begin{array}{c}0.02 \\
(0.01)\end{array}$ & $\begin{array}{l}0.06^{* *} \\
(0.02)\end{array}$ & $\begin{array}{c}0.04 \\
(0.06)\end{array}$ & $\begin{array}{c}0.01 \\
(0.02)\end{array}$ & $\begin{array}{c}0.15^{*} \\
(0.09)\end{array}$ \\
\hline$\beta$ & $\begin{array}{l}0.80^{* *} \\
(0.18)\end{array}$ & $\begin{array}{l}0.98 * * \\
(0.01)\end{array}$ & $\begin{array}{l}0.90 * * \\
(0.03)\end{array}$ & $\begin{array}{l}0.93 * * \\
(0.19)\end{array}$ & $\begin{array}{l}0.96 * * \\
(0.07)\end{array}$ & $\begin{array}{r}0.59^{+} \\
(0.31)\end{array}$ \\
\hline $\begin{array}{l}\text { Shape } \\
\text { Parameter }\end{array}$ & $\begin{array}{l}8.27 * * \\
(2.76)\end{array}$ & $\begin{array}{l}9.03 * * \\
(3.07)\end{array}$ & $\begin{array}{l}10.18^{* *} \\
(3.35)\end{array}$ & $\begin{array}{l}10.91 * * \\
(4.03)\end{array}$ & $\begin{array}{l}9.57 * * \\
(3.36)\end{array}$ & \\
\hline \multicolumn{7}{|c|}{ Constant correlation } \\
\hline$r^{2}$ & 0.66 & 0.76 & 0.91 & 0.83 & 0.70 & 0.76 \\
\hline
\end{tabular}

Note.-Cell entries are coefficient estimates, with standard errors in parentheses below. Model is fit in $R$ using the rmgarch and rugarch packages (Ghalanos 2013).

$h_{t}=c_{i}+a_{i} \varepsilon_{t-1}^{2}+b_{i} h_{t-1} . R_{t}=(1-\alpha-\beta) \bar{R}+\alpha \varepsilon_{t-1} \varepsilon_{t-1}^{c^{\prime}}+\beta R_{t-1} . R_{t} i s k \times k$ time varying correlation matrix. $\bar{R}$ is the unconditional covariance matrix. $h_{t}$ contains the time-varying standardized deviations.

${ }^{+} p<.10 ; * p<.05 ; * * p<.01$ 

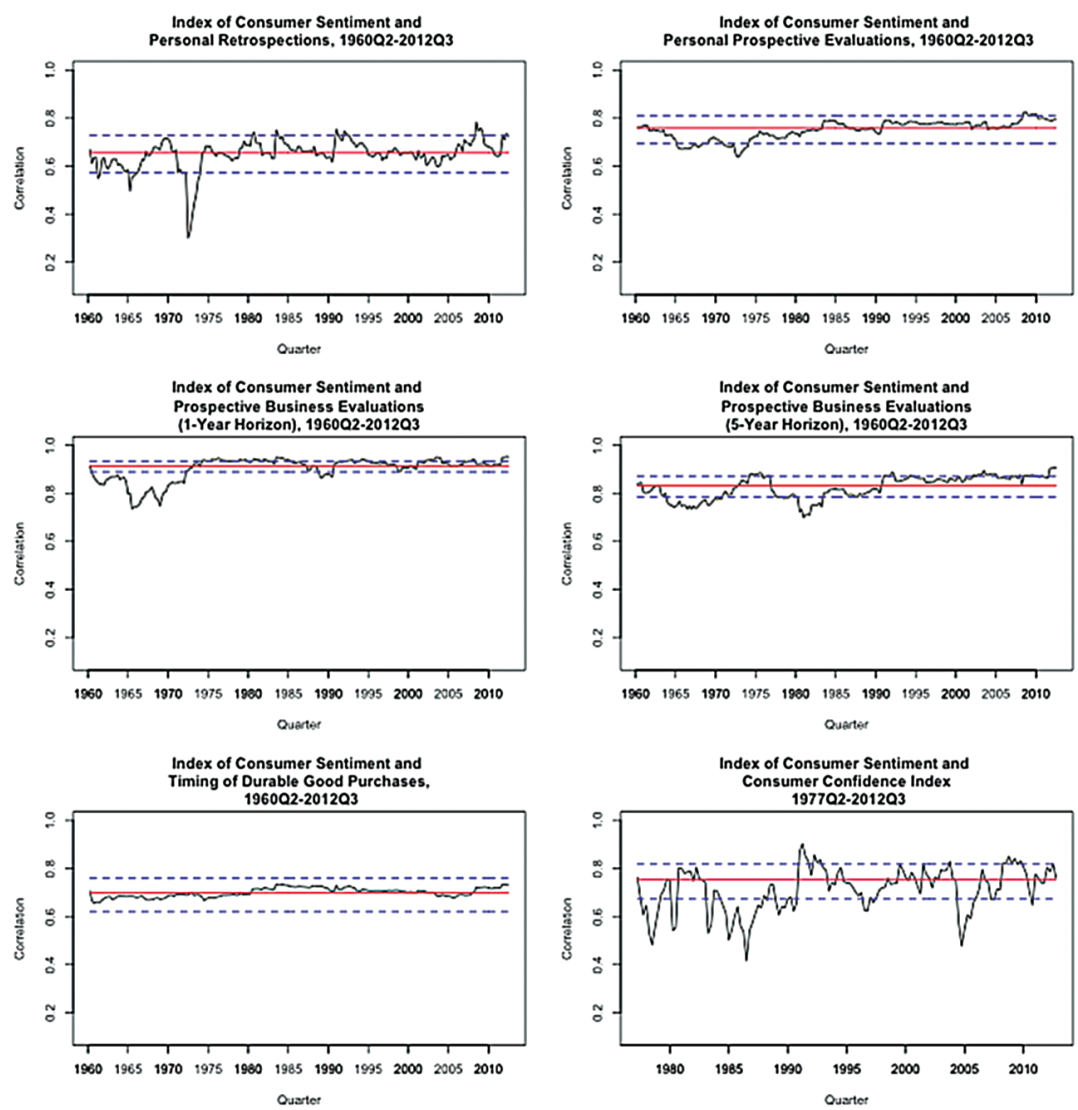

Figure 2. Dynamic Conditional Correlations.

Note also that, in matters of degree, the estimated constant (average) correlations reported in figure 2 are in fact very high, perhaps surprisingly so given that these correlations are estimated from data that are filtered to reflect the relationship between innovations in the series pairs. The average of the estimated dynamic correlations with the index range from a low of $r^{2} \approx 0.66$ for personal retrospective evaluations to $r^{2} \approx 0.91$ for one-year-out business expectations. These results, taken as a whole, suggest a high degree of internal reliability in the ICS.

\section{PARALLEL-FORM RELIABILITY}

The existence of a second measure of consumer confidence, the Conference Board's CCI, affords us a second opportunity to assess the repeatability of the 
ICS. To the extent that the two measures of consumer confidence in fact measure consumer confidence, they should exhibit a high degree of correlation and do so consistently over time. This type of reliability is formally referred to as parallel-form reliability. We can assess the reliability of both measures of consumer confidence by looking at the time-varying correlations between the ICS and CCI.

The evidence for parallel-form reliability is not strong. ${ }^{20}$ The estimates of the DCC parameters are both significant. The dynamic correlation between the ICS and CCI is persistent $(\beta=.59)$, but much less so than between the ICS and its components. The DCC estimate of the news parameter, $\alpha$, is also more than double that estimated in the previous pairings. New information affects the ICS and CCI differently, so that their correlation changes systematically over time-evidence against reliability.

We can see this in the graph of the estimated dynamic correlations as well (see the bottom-right panel of figure 2). While the average correlation is similar to the others estimated, the range is much wider over the shared time period of analysis. There are strong commonalities between the ICS and CCI, but the strength of the relationship varies over time so that these measures are not one and the same. The dynamic correlations range from 0.41 to 0.90 in this case, while in all other cases the range was less than half that. The correlations also frequently cross the confidence interval around the estimated unconditional correlation. In other words, the two indexes are not related to each other in the same way over time. This is consistent with other research noting that the CCI relies uniquely and disproportionately on measures affected by unemployment, thereby capturing something distinct from the ICS (Ludvigson 2004). ${ }^{21}$

\section{Assessing the Validity of the ICS}

Judgments about the validity of a measure like the ICS traditionally involve assessments of face validity, content validity, and predictive (or construct) validity. On its face, the ICS is clearly valid. As noted in the introduction,

20. We fixed the estimates of the autoregressive and (G)ARCH coefficients in this shorter time period to match those of the full time period, so as to use the more complete information about the underlying dynamics of the ICS available in the longer time series while allowing a different estimate of the mean. This explains the absence of standard errors for these estimates in the final column of the table.

21. The increased variability in the dynamic correlations of the CCI with the ICS when compared with the ICS component series may be partly a function of three features of the data. First, the component measures and the ICS are collected from the same survey so survey measurement errors likely will be correlated. Second, the sample size that is the basis for the CCI is approximately seven times that of the ICS. Third, while The Conference Board sends its survey to a random sample, no information is collected to determine the representativeness of the final sample. In addition, the differences in survey modes (the ICS data are collected by telephone while the CCI data are collected by mail) and dates of fieldwork within the quarter could also reduce the correlation. 
reporting on the monthly releases of the ICS is a common and routine feature of newscasts, and profit-seeking organizations are willing to pay for early access to the survey results. This suggests that the measure contains useful information about the beliefs of consumers and is, on the face of it, valid.

Our evaluation of the content validity of the ICS is mostly positive. If the underlying construct includes a consumer's beliefs about both his or her personal situation, and the situation of business conditions in the country as a whole, and the consumer's beliefs about both personal and national economic circumstances have both retrospective and prospective components, then consumer sentiment neatly forms a $2 \mathrm{X} 2$ grid. The five items that constitute the index, displayed in table 1, show that three of the four cells are covered in the index: personal/retrospective (item 2), personal/prospective (item 5), and business/prospective (items 3 and 4). The index does not contain the respondent's opinion about business conditions in the recent past. ${ }^{22}$ Moreover, the index includes an item that is not clearly a part of the $2 \mathrm{X} 2$ matrix--the question about whether or not now is a good time to buy household items.

Of course, the most crucial validity check for any measure is that of construct (or predictive) validity. We make that determination next. Specifically, we assess if (and how) the economic evaluations provide information about consumer behavior independent of economic conditions.

\section{CONSTRUCT (OR PREDICTIVE) VALIDITY}

Consumer spending, we know, depends on objective economic conditions. Positive economic signals lead to more spending, weaker signals to less. Consumer sentiment, in theory, captures something distinct or, at the very least, more-the willingness to spend. The well-developed theoretical construct embodied in consumer sentiment offers a clear prediction: Consumer sentiment should predict consumer spending, conditional on objective information about the economy. This suggests a straightforward test of construct validity.

Our strategy - and the typical strategy taken in the economics literatureis to first estimate a model of consumer-spending growth that is saturated by economic indicators. In the second step, we add sentiment to the model. If consumer sentiment predicts spending above and beyond the effects of other economic forces, we have strong evidence of its construct validity. The evidence to date on this score, as suggested at the outset of the article, is mixed. The economic literature has shown that consumer sentiment, under various conditions, considering different historical periods, analyzing different 
periodicity, and allowing for extraordinary conditions, defined in different ways, produces conflicting evidence with regard to predictive validity. ${ }^{23}$

Our purpose here is to offer a conservative test of the predictive validity of the ICS and to offer something new, via a comparison of the predictive validity of the Index of Consumer Sentiment with that of its components. As such, we parse the second-step models in two ways. We first consider the addition of the ICS, then model consumer spending as a function of the index components separately (and jointly). Comparing the performance of the ICS to the index components allows us to assess whether the index is more (or less) than the sum of its parts.

We focus our attention on modeling growth in spending on durable goods purchases. As Katona (1975) and others (Blanchard 1993; Hall 1993; Huth, Eppright, and Taube 1994; Eppright, Arguea, and Huth 1998; Adrangi and Macri 2011) have noted, this is precisely the type of spending where sentiment should matter most; these are the very things we can hold off buying when times are bad. Consumer sentiment should thus act to restrain this spending when we are pessimistic. In contrast, positive sentiment should lead to more consumption of durable goods.

Our model of spending growth is saturated with economic indicators capturing both current conditions and leading indicators. Specifically, we include two lags of spending growth on durable goods, as well as current and four lags of the Conference Board's Index of Lagging Economic Indicators (LEI): growth in disposable personal income, the quarterly inflation rate, the three-month Treasury Bill rate, and growth in unemployment. ${ }^{24}$ This baseline economicsonly model, not shown, has a root mean squared error (RMSE) of 1.524. Block $F$-tests on each of the economic variables show the index of LEI, growth in disposable personal income, and the quarterly inflation rate to have a significant effect on growth in spending on durable goods. Neither the three-month Treasury Bill rate nor growth in unemployment exerts a significant effect.

Column A of table 3 presents estimates of the effects of the ICS on consumerspending growth, along with the estimated effects of the two lags of spending growth. Not shown are the estimates of the remaining economic variables included in the model. ${ }^{25}$ Two features of this model are noteworthy. First, the estimated effect of the ICS is essentially zero, and is, in any case, statistically insignificant. Second, the RMSE from the model with the addition of the ICS is actually larger than the baseline, economics-only model (1.527 compared to 1.524).

23. Though it is impossible, here, to definitively conclude why the literature has yielded such disparate findings about the relationship between consumer sentiment and spending, our analytic strategy suggests one possible answer that merits exploration in future work, but is beyond the scope of the analysis here: that the relationship between consumer sentiment and spending is dynamic. Because all of the contradictory analyses mentioned at the outset of this article assume static relationships between consumer sentiment and spending, perhaps the resolution to this debate lies in making the relationship itself dynamic.

24. The LEI Index contains unemployment, so we include growth in unemployment rather than its levels in our models.

25. Details on the robustness of these findings are presented in the appendix. 
Table 3. The Subjective Causes of Consumer Spending

\begin{tabular}{|c|c|c|}
\hline Variable & $\begin{array}{c}(\mathrm{A}) \\
\text { Coeff. } \\
\text { (s.e.) }\end{array}$ & $\begin{array}{c}\text { (B) } \\
\text { Coeff. } \\
\text { (s.e.) }\end{array}$ \\
\hline Lagged dependent variable & $\begin{array}{l}0.506 * * \\
(0.077)\end{array}$ & $\begin{array}{c}0.486 * * \\
(0.077)\end{array}$ \\
\hline Second lagged dependent variable & $\begin{array}{c}-0.127^{+} \\
(0.075)\end{array}$ & $\begin{array}{c}-0.200 * \\
(0.078)\end{array}$ \\
\hline Index of Consumer Sentiment & $\begin{array}{c}-0.009 \\
(0.017)\end{array}$ & \\
\hline Personal expectations & & $\begin{array}{c}-0.031 \\
(0.034)\end{array}$ \\
\hline Personal retrospections & & $\begin{array}{c}-0.037 \\
(0.025)\end{array}$ \\
\hline 12-month business expectations & & $\begin{array}{l}0.045^{* *} \\
(0.016)\end{array}$ \\
\hline 5-year business expectations & & $\begin{array}{c}-0.047^{*} \\
(0.019)\end{array}$ \\
\hline Durable goods sentiment & & $\begin{array}{c}0.021 \\
(0.017)\end{array}$ \\
\hline Adj. $R^{2}$ & 0.796 & 0.808 \\
\hline RMSE & 1.527 & 1.483 \\
\hline Portmanteau $Q$ & 8.466 & 8.298 \\
\hline$p$-value & $(0.584)$ & $(0.600)$ \\
\hline$N$ & 198 & 198 \\
\hline
\end{tabular}

NotE.-Cell entries are coefficient estimates, with standard errors in parentheses. The dependent variable in these analyses is annualized growth in spending on durable goods, measured quarterly from the first quarter of 1960 through the third quarter of 2012.

$+p<.10 ; * p<.05 ; * * p<.01$

A different picture emerges, though, when the ICS is decomposed into its component parts. Those results are presented in column B. In that model, two of the five index components are statistically significantly related to growth in durable goods spending, and in ways that are largely intuitive. Expectations about the national economy one and five years out affect spending on durable goods. In the first case, as optimism about the next 12 months increases, on average people spend more in the present. Controlling for these attitudes, expectations for brighter conditions five years down the road lead people to hold off spending, so that growth in durable goods consumption drops in the current period, perhaps because consumers believe the better time to buy appliances or computers, for example, is in the future. Personal evaluations are not significantly related to growth in durable goods consumption.

Taken individually and as a collective, at least with respect to consumer spending on durable goods, the multi-indicator ICS predicts less well than do its components. The model in column B explains more of the variance 
in spending growth in durable goods, and the RMSE is smaller (1.483). It is important to note that the index components do not individually predict spending growth. The effects are conditional. Willingness to consume appears to be a complex construct, but — at least in this analysis — one that is better captured by the inclusion of multiple indicators than by the inclusion of the index created from those indicators. In this particular sense, the Index of Consumer Sentiment is less than the sum of its component parts. ${ }^{26}$

The magnitude of these effects is not trivial. A standard-deviation change in expectations regarding the state of the national economy in the next year (approximately 32 points) is associated with a shift in durable goods spending after accounting for economic conditions and controlling for other economic evaluations by almost one-and-a-half percent (annualized) from the previous period. In our view, this is a substantial effect. A standard-deviation change in expectations about the national economy five years out (just under 20 points over this time period) is associated with a drop in spending on durable goods of just under a percent in the current quarter. These effects are substantial; Shifts in spending patterns of one percent have large economic consequences, and are interpreted as such in media reports.

We know that we have set the bar high by including both a large number of economic indicators on the right-hand side of the model and including four lags. Perhaps, then, it is not surprising that the ICS does not add new information to the spending model. What is surprising is that consumer sentiment is more nuanced than most research has suggested. Specifically, our evidence is suggestive with regard to how consumers determine their willingness to consume. If our evidence is to be believed, consumers examine different time horizons in thinking about whether to make large purchases now.

\section{Conclusions}

On March 1, 2013, a widely printed headline featured the ICS: "US Michigan Consumer Sentiment Rises above Estimate." The article went on to state that "Confidence among American households rose more than projected in February in a gain that could boost consumer buying, the largest part of the economy." Stories like these that link sentiment to spending (and economic conditions more broadly) have been a regular feature of media reports on the state of the economy for 50 years. Political fortunes, too, are linked to consumer sentiment by the media. Just prior to the 2012 election, NBCNews. com reported that "US consumer sentiment unexpectedly rose to its highest in five years in October in the latest in a string of encouraging signs from the economy that may boost President Barack Obama's re-election hopes next

26. Chua and Tsiaplias (2009) also find that disaggregating consumer-sentiment data improves the ability to forecast GDP consumption (as well as GDP) in Australia, which of course uses different measures than the US-focused ICS. 
month." Scholarly research, too, has found evidence that consumer sentiment influences the economy and the fortunes of political incumbents.

Consumer sentiment is clearly a meaningful concept, particularly as a dynamic concept. There are times when the public is optimistic about the economy, and times when it is pessimistic. Consumer sentiment ebbs and flows with our knowledge of economic history, most recently by dipping to some of its lowest historic values during the recession that ushered in President Obama. And, absent any information on objective economic indicators, some variant of consumer sentiment predicts spending.

But how useful is the most prominent measure of consumer sentiment to the scholar or investor trying to predict the future or to politicians trying to turn around a sagging economy? We have broached this question by examining the Index of Consumer Sentiment and its component series, considering theoretical foundations, measurement, and in particular the evidence for the reliability and validity of the construct and measures.

As in most exercises of this sort, the evidence is qualified. First and foremost, the ICS and its component measures do seem to capture the same things in the same way over most of their history, as indicated by the dynamic conditional correlations. If the ICS captures "willingness to consume," it has done so consistently since its inception. This has been true during periods of recession and expansion, during political and economic turmoil, and during elections. This is really quite remarkable. The two indicators measuring expectations about the future of the national economy are more strongly related to the index in an absolute sense than are the remaining three series, but all are highly correlated with the index (and each other), even after filtering the time-series dynamics from each series.

Yet the components of the ICS do not, in the strict sense, relate to the index in the same way over time. Those relationships are all dynamic. Parsing out systematic causes of these dynamics - and possibly using that information to generate a new index-is an exercise that awaits future analysis. The substantial volatility in the relationship between the ICS and the next-most-prominent measure of consumer sentiment-theCCI-is striking. The two measures do not appear to capture the same type of sentiment about the economy or to tap it in the same way. While this may be due in part to the unique choices made by the survey organizations with regard to survey administration and data collection, even setting these differences aside, we should not conclude either measure is problematic. Their distinct behavior does imply that they (at least partially) measure something different. The focus on unemployment in the component measures of the CCI offers the likely source of the explanation. Those reflecting on these surveys when gazing into their crystal balls to predict citizens' willingness to consume would do well to keep this distinction in mind. ${ }^{27}$

27. Further, the observation that these seemingly innocuous choices about how to administer the survey and collect the data might produce such variability in the correlations should also give pause to prognosticators using any single measure of consumer sentiment to forecast economic outcomes. 
Whether the ICS captures "willingness to consume" is less clear from our analysis. We have created a difficult test, to be sure, but we have done so with spending on durable goods-precisely the type of spending where we expect sentiment to matter most. Economic conditions anchor spending decisions. Adding current sentiment as measured by the ICS adds nothing to our crystal ball. By contrast, the component series taken collectively contain useful information about spending behavior. In short, the index is less useful, statistically, than are the component pieces. But so, too, is any given indicator less than the five considered as a set. This suggests the possibility that a better sentiment index could be created, assuming our goal is to predict durable goods spending. This is, assuredly, only one way a sentiment index can be useful.

In the end, we advise practitioners against the uncritical use of the ICS as a composite measure in their analyses, and prescribe instead that analysts consider using some subset of the component indicators, depending on the theoretical question at hand. In general, when speaking theoretically about how "consumer confidence" might influence some other concept, analysts might be able to be more specific, and refer instead to how "optimism about the economic future" or "positive recollections about the direction of the economy" might be a more specific substitute. In at least this one analysis-and, we speculate, perhaps in others- the whole of the ICS is something less than the sum of its component parts. 


\section{Appendix}

Table A1. The Subjective Causes of Consumer Spending: AR(2) GARCH(1,1) Models

\begin{tabular}{|c|c|c|}
\hline & (A) & (B) \\
\hline Variable & $\begin{array}{l}\text { Coeff. } \\
\text { (s.e.) }\end{array}$ & $\begin{array}{l}\text { Coeff. } \\
\text { (s.e.) }\end{array}$ \\
\hline Index of Consumer Sentiment & $\begin{array}{c}-0.015 \\
(0.026)\end{array}$ & \\
\hline Personal expectations & & $\begin{array}{r}-0.064^{+} \\
(0.035)\end{array}$ \\
\hline Personal retrospections & & $\begin{array}{c}0.015 \\
(0.030)\end{array}$ \\
\hline 12-month business expectations & & $\begin{array}{c}0.037^{* *} \\
(0.022)\end{array}$ \\
\hline 5-year business expectations & & $\begin{array}{r}-0.048^{+} \\
(0.026)\end{array}$ \\
\hline Durable goods sentiment & & $\begin{array}{c}0.001 \\
(0.018)\end{array}$ \\
\hline $\operatorname{AR}(1)$ & $\begin{array}{c}0.484^{* *} \\
(0.088)\end{array}$ & $\begin{array}{c}0.419^{* *} \\
(0.098)\end{array}$ \\
\hline $\operatorname{AR}(2)$ & $\begin{array}{c}-0.019 \\
(0.090)\end{array}$ & $\begin{array}{c}-0.029 \\
(0.091)\end{array}$ \\
\hline $\mathrm{ARCH}$ & $\begin{array}{c}0.121 \\
(0.076)\end{array}$ & $\begin{array}{r}0.097^{*} \\
(0.055)\end{array}$ \\
\hline GARCH & $\begin{array}{c}0.819^{* * *} \\
(0.107)\end{array}$ & $\begin{array}{c}0.868^{* *} \\
(0.077)\end{array}$ \\
\hline Wald $\chi^{2}$ & 316.10 & 414.36 \\
\hline Log likelihood & -343.329 & -338.424 \\
\hline Portmanteau $Q$ & 13.833 & 11.264 \\
\hline$\chi^{2}$ & $(0.181)$ & $(0.337)$ \\
\hline$N$ & 198 & 198 \\
\hline
\end{tabular}

NoTE.-Cell entries are coefficient estimates, with standard errors in parentheses. The dependent variable in these analyses is annualized growth in spending on durable goods, measured quarterly from the first quarter of 1960 through the third quarter of 2012.

${ }^{+} p<.10 ; * p<.05 ; * * p<.01$

\section{References}

Adams, F. Gerard, and Edward W. Green. 1965. "Explaining and Predicting Aggregative Consumer Attitudes." International Economic Review 6:275-93.

Adrangi, Bahram, and Joseph Macri. 2011. "Consumer Confidence and Aggregate Consumption Expenditures in the United States." Review of Economics \& Finance 1:1-18.

Antilla, Susan. 1991. "Consumer Statistics Hot on Wall Street." USA Today, November 5, 8B.

Blanchard, Olivier. 1993. "Consumption and the Recession of 1990-1991." American Economic Review 83:270-74. 
Bram, Jason, and Sydney Ludvigson. 1998. "Does Consumer Confidence Forecast Household Expenditure? A Sentiment Index Horse Race." Economic Policy Review-Federal Reserve Bank of New York 4:59-78.

Bryant, W.D. Anthony, and Joseph Macri. 2005. "Does Sentiment Explain Consumption?" Journal of Economics and Finance 29:97-111.

Carroll, Christopher D., Jeffrey C. Fuhrer, and David W. Wilcox. 1994. "Does Consumer Sentiment Forecast Household Spending? If So, Why?" American Economic Review 84:1397-1408.

Chua, Chew L., and Sarantis Tsiaplias. 2009. "Can Consumer Sentiment and Its Components Forecast Australian GDP and Consumption?" Journal of Forecasting 28:698-711.

Cohen, Sarah. 1995. "Consumer Surveys Don’t Always Give Expert Opinions.” St. Petersburg Times, November 1, 1E.

Curtin, Richard. 2008. Economic Discontent: Causes and Consequences. Technical Report, University of Michigan.

De Boef, Suzanna, and Paul M. Kellstedt. 2004. "The Political (and Economic) Origins of Consumer Confidence." American Journal of Political Science 48:633-49.

Desroches, Brigitte, and Marc-Andre Gosselin. 2002. "The Usefulness of Consumer Confidence Indexes in the United States." Bank of Canada, Working Papers 22:1-25.

Didow, Nicholas M., and George Franke. 1984. "Measurement Issues in Time-Series Research: Reliability and Validity Assessment in Modeling the Macroeconomic Effects of Advertising." Journal of Marketing Research 21:12-19.

Durr, Robert H. 1993. "What Moves Policy Sentiment?" American Political Science Review 87:158-70.

Durr, Robert H., John B. Gilmour, and Christina Wolbrecht. 1997. "Explaining Congressional Approval." American Journal of Political Science 41:175-207.

Easaw, Joshy Z., Dean Garratt, and Saeed M. Heravi. 2005. "Does Consumer Sentiment Accurately Forecast UK Household Consumption? Are There Any Comparisons to be Made with the US?" Journal of Macroeconomics 27:517-32.

Easaw, Joshy Z., and Saeed M. Heravi. 2004. "Evaluating Consumer Sentiments as Predictors of UK Household Consumption Behavior: Are They Accurate and Useful?" International Journal of Forecasting 20:671-81.

Engle, Robert F., and Kevin Sheppard. 2003. "Theoretical Properties of Dynamic Conditional Correlation Multivariate GARCH." Technical Report, New York University and Oxford University.

Enns, Peter K., Paul M. Kellstedt, and Gregory E. McAvoy. 2012. "The Consequences of Partisanship in Economic Perceptions." Public Opinion Quarterly 76:287-310.

Eppright, David R., Nestor M. Arguea, and William L. Huth. 1998. "Aggregate Consumer Expectation Indexes as Indicators of Future Consumer Expenditures.” Journal of Economic Psychology 19:215-35.

Erikson, Robert S., Michael B. MacKuen, and James A. Stimson. 2002. The Macro Polity. New York: Cambridge University Press.

Garner, C. Alan. 1991. "Forecasting Consumer Spending: Should Economists Pay Attention to Consumer Confidence Surveys?" Economic Review-Federal Reserve Bank of Kansas City 76(3):57.

Ghalanos, Alexios. 2013. rmgarch: Multivariate GARCH models. R package version 1.2-0.

Hall, Robert E. 1993. "Macro Theory and the Recession of 1990-1991." American Economic Review 83:275-79.

Hardouvelis, Gikas A., and Dimitrios D. Thomakos. 2008. "Consumer Confidence and Elections." Centre for Economic Policy Research Discussion Paper (DP6701).

Hosseini, Hamid. 2003. "The Arrival of Behavioral Economics: From Michigan, or the Carnegie School in the 1950s and the Early 1960s?" Journal of Socio-Economics 32:391-409. 
Huth, William L., David R. Eppright, and Paul M. Taube. 1994. "The Indexes of Consumer Sentiment and Confidence: Leading or Misleading Guides to Future Buyer Behavior.” Journal of Business Research 29:199-206.

Jansen, W. Jos, and Niek J. Nahuis. 2003. "The Stock Market and Consumer Confidence: European Evidence.” Economics Letters 79:89-98.

Kahneman, Daniel, and Amos Tversky. 1973. "On the Psychology of Prediction." Psychological Review 80:237-51.

Katona, George. 1975. Psychological Economics. Oxford: Elsevier.

Keele, Luke, and Nathan J. Kelly. 2006. "Dynamic Models for Dynamic Theories: The Ins and Outs of Lagged Dependent Variables.” Political Analysis 14:186-205.

Ladner, Matthew, and Christopher Wlezien. 2007. "Partisan Preferences, Electoral Prospects, and Economic Expectations." Comparative Political Studies 40:571-96.

Lebo, Matthew J., and Janet M. Box-Steffensmeier. 2008. "Dynamic Conditional Correlations in Political Science.” American Journal of Political Science 52:688-704.

Likert, Rensis. 1972. "Courageous Pioneer: Creating a New Field of Knowledge.” In Human Behavior in Economic Affairs: Essays in Honor of George Katona, edited by Burkhard Strumpel, James N. Morgan, and Ernest Zahn, 3-9. San Francisco: Jossey-Bass.

Loria, Eduardo, and Luis Brito. 2004. "Is the Consumer Confidence Index a Sound Predictor of the Private Demand in the United States?" Estudios de Economía Aplicada 22:795-809.

Ludvigson, Sydney C. 2004. "Consumer Confidence and Consumer Spending." Journal of Economic Perspectives 18:29-50.

MacKuen, Michael B., Robert S. Erikson, and James A. Stimson. 1992. "Peasants or Bankers? The American Electorate and the US Economy." American Political Science Review 86:597-611.

Morin, Richard. 1992. "A Matter of Consumer Confidence, But Does It Really Matter?" Washington Post, April 3, page A19.

Simon, Herbert A. 1951. Models of Man. New York: Wiley.

___ 1955. "A Behavioral Model of Rational Choice." Quarterly Journal of Economics 69:99-118.

Throop, Adrian W. 1992. "Consumer Sentiment: Its Causes and Effects." Economic Review 1:35-59.

Wlezien, Christopher, Mark Franklin, and Daniel Twiggs. 1997. "Economic Perceptions and Vote Choice: Disentangling the Endogeneity.” Political Behavior 19:7-17.

Worthen, Blain R., Walter R. Borg, and Karl White. 1993. Measurement and Evaluation in the Schools. New York: Longman. 